\title{
ANÁLISE DA GERAÇÃO DE RESÍDUOS SÓLIDOS DA CONSTRUÇÃO CIVIL EM TERESINA, PIAUÍ
}

\author{
A. S. G. MESQUITA
}

Instituto Federal do Piauí

E-mail: atilamesquista@hotmail.com

Artigo submetido em fevereiro/2012 e aceito em maio/2012

\section{RESUMO}

Os resíduos sólidos da construção civil apresentam grandes problemas ambientais devido principalmente a grande quantidade produzida e destinação inadequada. Este trabalho objetiva conhecer as características dos entulhos gerados na cidade de Teresina, assim como a sua quantificação e possíveis impactos ambientais. O estudo foi realizado em uma construção de um prédio residencial de 19 pavimentos, durante as fases de revestimento (assentamento de contrapiso) e concretagem (laje e rampa). Na fase de revestimento observou-se uma perda $0,66 \%$ do material utilizado. Na fase de concretagem o desperdício foi de 1,25\%. Daí conclui-se que a indústria de construção civil de Teresina apresenta um patamar elevado de desperdício, considerando o custo desses elementos de obra e o grande impacto ambiental associado.

PALAVRAS-CHAVE: resíduos sólidos; entulho; Teresina; construção civil.

\section{ANALYSIS OF SOLID RESIDUES GENERATION OF CIVIL CONSTRUCTION IN TERESINA, PIAUÍ}

\section{ABSTRACT}

The solid residues of the civil construction present great environmental problems owed the great produced amount and inadequate destination mainly. This work objectifies to know the characteristics of the dumps generated in the city of Teresina, as well as its quantification and possible environmental impacts. The study was accomplished in a construction of a residential building of 19 pavements, during the coating phases (against floor establishment) and concrete (flagstone and ramp). In the coating phase a loss of $0,66 \%$ of the used material. In the concrete phase the waste was of $1,25 \%$. Of there it is ended that the industry of civil construction is an enormous one generating of residues, or dump, that you/they are commonly thrown in the atmosphere.

KEY-WORDS: solid residues; dump; Teresina; civil construction. 


\section{ANÁLISE DA GERAÇÃO DE RESÍDUOS SÓLIDOS DA CONSTRUÇÃO CIVIL EM TERESINA, PIAUÍ}

\section{INTRODUÇÃO}

No Brasil, a construção civil é responsável por cerca de $14 \%$ do PIB nacional. O setor também é um dos maiores consumidores de matérias-primas naturais. Estima-se que sejam utilizados entre $20 \%$ e $50 \%$ do total de recursos naturais consumidos pela sociedade. A indústria da construção civil também gera impactos no meio ambiente com a produção de resíduos, que se tornou um grande problema nas grandes cidades. O entulho chega a representar $60 \%$ dos resíduos sólidos urbanos produzidos. Segundo dados internacionais, segundo Pinto (2005), o total de geração de resíduos varia de 163 a mais de 300 quilos por habitante/ano.

O processo de produção da indústria da construção civil causa impacto ao meio ambiente ao longo de toda sua cadeia produtiva. Ao ocupar-se de terras, extrair e processar matéria-prima, construir e usar edifícios, recursos naturais são explorados e resíduos são gerados afetando o ar, o clima, o lençol freático, o solo, a paisagem, a fauna, a flora, e, sobretudo, prejudicando o hábitat humano. Estes impactos são mais visíveis em áreas de baixa renda e em áreas urbanas degradadas. Sendo os resíduos provenientes desta atividade o principal aspecto ambiental motivador desse tipo de desequilíbrio.

Esse dito resíduo ou entulho de construção civil é um tipo de resíduo sólido urbano, dentre vários existentes, definido segundo Levy \& Helene (1997) apud Angulo (1998) como "sobras ou rejeitos constituídos por todo material mineral oriundo do desperdício inerente ao processo construtivo adotado na obra nova ou de reformas ou demolições".

O Conselho Nacional do Meio Ambiente - CONAMA conceitua na resolução 307/2002, resíduos da construção civil como "os provenientes de construções, reformas, reparos e demolições de obras de construção civil, e os resultantes da preparação e da escavação de terrenos tais como: tijolos, blocos cerâmicos, concreto em geral, solos, rochas, metais, resinas, colas, tintas, madeiras e compensados, forros, argamassa, gesso, telhas, pavimento asfáltico, vidros, plásticos, tubulações, fiação elétrica etc., comumente chamados de entulhos de obras, caliça ou metralha". Logo, praticamente todas as atividades desenvolvidas no setor da construção civil são geradoras de entulho. No processo construtivo, o alto índice de perdas do setor é a principal causa do entulho gerado, conforme Angulo (1998).

A composição média dos resíduos de construção varia conforme a região e o período de análise, não sendo possível a fixação de valores definitivos para a porcentagem dos diversos componentes. Mesmo para um mesmo local de amostragem pode-se ter grandes variações na participação de alguns materiais. Isto pode dificultar até mesmo a determinação de faixas para as porcentagens dos diferentes tipos de resíduos.

A quantidade de entulho gerada nas cidades brasileiras é muito significativa e pode servir como um indicador do desperdício de materiais. Os resíduos produzidos pela Indústria de Construção variam entre $41 \%$ e $70 \%$ da massa total de resíduos sólidos urbanos. Pinto (1987), 
acrescenta que "a quantidade de resíduos liberados pelas atividades construtivas nas cidades é de tal porte que, se previsto uma reutilização do material gerado, as necessidades de pavimentação de novas vias ou construção de habitações de interesse social, seriam totalmente satisfeitas".

Ainda assim, é comum a disposição irregular de entulho na maioria das cidades do país, por este motivo, esses resíduos são considerados um problema de limpeza pública, acarretando uma série de inconvenientes para toda a sociedade, tais como: altos custos para o sistema de limpeza urbana, saúde pública, enchentes, assoreamento e contaminação de cursos d'água, contaminação de solo, erosão, obstrução de sistemas de drenagem urbanos, dentre outros.

Segundo Pinto (1999), não existem levantamentos precisos que permitam deduzir a exata produção dos diversos agentes atuantes na construção, o que impossibilita uma análise global do volume de resíduos sólidos gerados pela construção civil nas áreas urbanas brasileiras. Os números coletados pelo INSS - Instituto Nacional de Seguridade Social, através do recolhimento de taxas tidas como "obrigatórias", são absolutamente irreais, e os registros das municipalidades, através da aprovação de projetos, revelam apenas a parte formal da produção de edificações. Dificultando um correto dimensionamento de medidas mitigadoras para um controle eficiente deste cenário ambiental.

No entanto, a agregação dessas informações parcelares sistematizadas pelas municipalidades com informações recolhidas entre os agentes coletores dos resíduos de construção e demolição permite a construção de um indicador confiável da intensidade de boa parte da atividade construtiva e do volume de resíduos por ela gerado. O método de quantificação dos resíduos pode ser aplicado a qualquer município que mantenha registros rotineiros da construção licenciada e que possibilite o acesso aos agentes empresariais, autônomos ou públicos que realizam a remoção dos resíduos gerados nos diversos tipos de atividades construtivas.

A cidade de Teresina, nesse contexto não se apresenta com um cenário alheio a tais condições, e nos últimos anos vem passando por um processo acelerado de verticalização, onde se observa construções de enormes prédios residenciais em toda a zona urbana, acompanhada da geração de uma grande quantidade de resíduos de construção. De acordo com dados fornecidos pela Prefeitura Municipal de Teresina (PMT), o município produz uma média mensal de 5.392 toneladas de entulhos que são lançados no "aterro sanitário" ou em locais que precisam ser aterrados.

Oficialmente a coleta de entulho iniciou-se no final da década de 90, onde a Prefeitura deu uma concessão para empresas coletoras. A primeira empresa de coleta na cidade foi a Disk Entulho, posteriormente a Tirentulho e por último a Papa Entulho. Embora tal alternativa seja muito importante dar uma destinação adequada aos resíduos gerados, torna-se imperativas ações que proponham à sua redução diretamente na fonte de geração, ou seja, nos próprios canteiros de obras, que somadas às ações de adequar a destinação desses resíduos, podem contribuir significativamente para a redução do impacto da atividade construtiva no meio ambiente. 
No Piauí, notadamente em Teresina, poucos estudos têm sido feito no que diz respeito à avaliação dos resíduos sólidos da construção civil, por isso, este trabalho reveste-se de suma importância, uma vez que a caracterização dos resíduos e o conhecimento do potencial de aproveitamento, identificando os fatores limitantes do uso e aplicação, servirão para adoção de medidas que visem à minimização, o reuso ou a reciclagem dos materiais possibilitando ganhos econômico e ambiental.

Sendo assim, neste trabalho são apresentadas as características dos resíduos sólidos gerados na construção civil na cidade de Teresina. Sendo quantificados os resíduos sólidos produzidos de acordo com a etapa da construção e calculados os percentuais correspondentes. Bem como, feita a verificação dos impactos ambientais ocorridos pela destinação final dos resíduos sólidos produzidos durante a construção.

\section{METODOLOGIA}

O trabalho consistiu de um levantamento de dados, em obras escolhidas por meio de estruturação deliberada e sistemática. O principal levantamento foi realizado no canteiro de obra de um condomínio residencial localizado no bairro Jockey na zona Leste de Teresina--PI. O prédio possui 19 pavimentos, sendo o $1^{\circ}$ e destinado à garagem, o $2^{\circ}$ ao salão de festas, do $3^{\circ}$ ao 160 são apartamentos duplex quatro por andar, o $17^{\circ}$ e $18^{\circ}$ apartamento duplex dois por andar e o 19 a cobertura. O condomínio apresenta uma área total de 4.351,09 $\mathrm{m}^{2}$ com apartamentos de 71,30 $\mathrm{m}^{2}$ distribuídos.

A pesquisa foi realizada na fase de revestimento e concretagem, especificamente o contra piso dos apartamentos duplex (laje inferior e superior, ou seja, em dois pavimentos) quatro por andar e a concretagem da rampa e da laje de acesso à garagem, 10 pavimento.

Considerou-se a fase de construção e a área construída, a fim de comparar os materiais utilizados com os desperdiçados, baseando-se em valores teóricos de consumo utilizado em orçamentos e pela quantidade de materiais adquiridos.

Calculou-se a quantidade de material solicitado em quilos, tendo como base a quantidade de traços (medida de dosagem dos elementos que compõem argamassas e concretos) utilizados para cada etapa. Fizeram-se as medições de perda de cada fase.

As medidas de areia, na etapa de contrapiso, e as de areia e seixo, na de concretagem, foram usadas padiolas específicas em cada traço, para se obter o peso em quilos dos traços adotou-se o seguinte procedimento:

1. Usou-se um recipiente com capacidade de 1 litro.

2. Pesou-se o recipiente (com o volume de 1 litro) com a areia e depois com o seixo. Anotou-se o resultado.

3. Transformou-se o volume do recipiente, que era em litro, para metros cúbicos.

4. Tiraram-se as medidas das padiolas e calcularam-se os seus volumes em metros cúbicos. 
5. Considerando-se a relação linear, fez-se a correlação para obtenção da massa de cada material na padiola, em quilogramas.

6. Para o cálculo das perdas de contrapiso, recolheu-se as sobras de todo o contrapiso de um apartamento e fez-se a medição em um recipiente com capacidade para 18 litros. Já para o cálculo da perda de concreto a sobra foi depositada em um carro-de-mão com capacidade de $0,090 \mathrm{~m}^{3}$ (Figura 1 ).

Para a determinação da massa de sobras de contrapiso e concreto utilizou-se do procedimento descrito abaixo:

1. Aferiu-se um recipiente com capacidade de 1 litro.

2. Pesou-se o recipiente (com o volume de 1 litro) com contrapiso e logo em seguida com concreto. Anotou-se o resultado.

3. Transformou-se o volume do recipiente, em metros cúbicos.

4. Tirou-se as medidas do recipiente usado para medir a sobra de contrapiso, e as medidas do carro-de-mão usado para medir as sobras de concreto. Calcularam-se os seus volumes em metros cúbicos.

5. Fez-se a correção para determinação da massa de cada material nos recipientes mencionados.

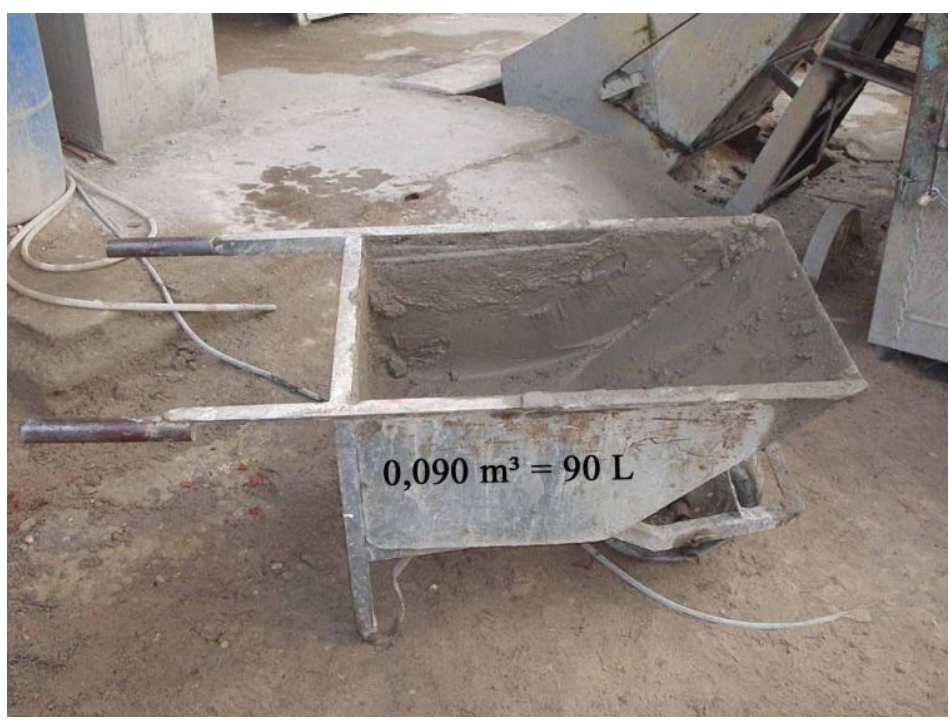

Figura 01 - Carro-de-mão usada para medir a perda de concreto.

\section{RESULTADOS OBTIDOS}

Com base nos resultados médios das inspeções e experimentos de quantificações, obtevese os resultados descritos nesse tópico. Na fase de revestimento foi verificado o assentamento de contrapiso de apartamentos do tipo duplex, quatro por andar, com área de $71,30 \mathrm{~m}^{2}$. Para essa etapa foram utilizados nove traços de contrapiso. Para a verificação do material desperdiçado foi necessário o conhecimento da quantidade dos materiais utilizados para a produção de 1 traço, que estão descritos na Tabela 1. 
Tabela 1 - Materiais utilizados para a produção de "1 traço" de contrapiso.

\begin{tabular}{|c|c|c|}
\hline Materiais & Quantidade & Total $(\mathrm{kg})$ \\
\hline Cimento & 1 saco & $50 \mathrm{~kg}$ \\
\hline Areia & 3 padiolas & $350,4 \mathrm{~kg}$ \\
\hline Água & 20 litros & $20 \mathrm{~kg}$ \\
\hline \multicolumn{2}{|c|}{ TOTAL } & $420,4 \mathrm{~kg}$ \\
\hline
\end{tabular}

Os resíduos de contrapiso produzidos em um apartamento foram medidos em um recipiente com capacidade para 18 litros, obtendo-se a massa de 1,4 kg/L, ou seja, em um apartamento tem-se a sobra total de $25,2 \mathrm{~kg}$. Como o condomínio possui um total de 28 apartamentos estima-se uma perda de $705,6 \mathrm{Kg}$ na execução do contrapiso dos apartamentos duplex quatro por andar. Calculando-se a porcentagem de perda de cada apartamento o valor resultante é de $0,66 \%$.

$\mathrm{Na}$ fase de concretagem foi verificada a colocação de concreto na rampa e na laje que dão acesso à garagem ( $1^{\circ}$ pavimento), as duas possuem área total de $43,89 \mathrm{~m}^{2}$ e foram utilizados 25 traços de concreto.

Tabela 2 - Materiais utilizados para a produção de "1 traço" de concreto

\begin{tabular}{|c|c|c|}
\hline Materiais & Quantidade & Total $(\mathrm{kg})$ \\
\hline Cimento & 1 saco & $\mathbf{5 0} \mathbf{~ k g}$ \\
\hline Areia & 2 padiolas & $\mathbf{1 1 5 , 2} \mathbf{~ k g}$ \\
\hline Seixo & 2 padiolas & $\mathbf{1 1 4} \mathbf{~ k g}$ \\
\hline Água & 20 litros & $\mathbf{2 0 ~} \mathbf{2 g}$ \\
\hline \multicolumn{2}{|c|}{ TOTAL } & $\mathbf{2 9 9 , 2} \mathbf{~ g ~}$ \\
\hline
\end{tabular}

Os resíduos de concreto produzidos na concretagem da laje e da rampa foram medidos em um carro-de-mão com volume de $0,090 \mathrm{~m}^{3}$, ou seja, uma capacidade de 90 litros, sendo a massa de concreto $1,37 \mathrm{~kg} / \mathrm{L}$ obteve-se $123,3 \mathrm{~kg}$ para o volume do carro de mão. Calculando a porcentagem de perdas na concretagem da laje e da rampa o valor resultante é de 1,65\%.

$\mathrm{Na}$ Tabela 3 são apresentados os resultados obtidos com o referido levantamento, consolidando o levantamento em questão. Considerando as relações padrões de produção da construção civil e práticas sugeridas no PBQP-H, tais valores para a referência obtida em TeresinaPI são consideradas elevadas. Visto que impõe níveis elevados de produção de resíduos e um custo adicional ao processo de edificação para a amostragem considerada.

Tabela 3 - Quantidade de materiais desperdiçados nas etapas estudadas

\begin{tabular}{|c|c|c|c|}
\hline Etapas & $\begin{array}{c}\text { Materiais utilizados } \\
(\mathrm{kg})\end{array}$ & $\begin{array}{c}\text { Quantidade de } \\
\text { materiais } \\
\text { desperdiçados }(\mathrm{kg})\end{array}$ & $\begin{array}{c}\text { Porcentagem de } \\
\text { desperdiçio }\end{array}$ \\
\hline Contra piso & $\mathbf{3 . 7 8 3 , 6 ~ k g}$ & $\mathbf{2 5 , 2} \mathbf{~ k g}$ & $\mathbf{0 , 6 6 \%}$ \\
\hline Concretagem & $\mathbf{7 . 4 8 0} \mathbf{~ k g}$ & $\mathbf{1 2 3 , 3} \mathbf{~ k g}$ & $\mathbf{1 , 6 5 \%}$ \\
\hline
\end{tabular}


Sendo assim, fazem-se necessárias ações de bloqueio e redução na fonte para conter os níveis de desperdícios apresentados nas etapas de produção do contra piso e concretagem, na atividade da construção civil.

\section{CONCLUSÕES}

Através do estudo da caracterização e quantificação dos resíduos constatou-se que a quantidade de entulho varia de tipo e volume de acordo com a fase em que se encontra a construção. No trabalho foi verificada a fase de revestimento e de concretagem. Na primeira obteve-se um percentual de perda de $0,66 \%$. Na outra fase, apesar da área construída ser bem menor teve-se um percentual de $1,25 \%$, o que se conclui que a fase de concretagem produz bem mais resíduos do que a de revestimento. Percebeu-se também que há perdas inevitáveis e que a maior parte do entulho é gerada por erros ou indefinições na elaboração dos projetos e na sua execução.

Os índices de perdas apesar de aparentemente baixos, são bastante significativos visto que foram constatados que apenas no assentamento de contrapiso (fase de revestimento) dos 28 apartamentos, duplex 4 por andar, obtiveram-se 705,6 Kg de entulho, ou seja, se considerarmos todas as fases em todas as construções realizadas na cidade, tem-se quantidades representativas de entulhos lançados no ambiente.

Considerando que todo o entulho produzido nas obras é depositado em contêineres de empresa privada para posteriormente ser destinado ao "aterro sanitário" ou em áreas que necessitam de aterragem a pedido da Prefeitura Municipal ou por munícipes, este provoca diversos problemas, principalmente o esgotamento acelerado da área do aterro.

Para o uso do entulho como aterro devem-se ter preocupações com o controle técnico do processo com o objetivo de evitar problemas futuros nas construções erigidas nestas áreas ou até mesmo acidentes como o desabamento. A prática de aterragem nem sempre é a mais racional, pois o entulho pode servir para substituir materiais extraídos de jazidas, ou pode se transformar em matéria-prima para componentes de construção de qualidade similar aos materiais tradicionais.

Embora a reciclagem seja a melhor solução para o problema da disposição final do entulho, em Teresina ainda não existe nenhuma central de reciclagem desse material. Esse fato talvez pelo alto investimento que se tem de aplicar fazendo com que construtores não apostem nessa alternativa ou talvez pelo fato de que o volume de obras realizadas na cidade ainda não produza resíduos em escala suficiente para justificar a reciclagem.

Uma outra opção de solução seria a criação de um aterro de resíduos sólidos, como medida emergencial para o problema da deposição do entulho no aterro sanitário. De acordo com a Resolução 307/02 do CONAMA este aterro é uma área onde são empregadas técnicas de disposição de resíduos de construção civil Classe " $A$ " no solo. Esse tipo de aterro é mais barato que o sanitário e a concentração dos resíduos em um único local facilitaria a execução de projetos que visem à reutilização ou a reciclagem, uma vez que esses materiais são uma grande 
fonte de matéria prima a um baixo custo relativo.

\section{REFERÊNCIAS BIBLIOGRÁFICAS}

1. ANGULO, Sérgio Cirelli. Produção de concretos de agregados reciclados. 1998. 84 f.. Trabalho de Conclusão (Engenharia Civil) - Universidade Estadual de Londrina, Londrina.

2. ARAÚJO, Alexandre Feller de. A aplicação da metodologia de produção mais limpa: estudo em uma empresa do setor de construção civil. 2002. 120f.. Dissertação (Mestrado em Engenharia de Produção) - Universidade Federal de Santa, Florianópolis.

3. BAUER, Falcão L. A. Materiais de construção. 5 ed. revisada. Rio de Janeiro: LTC, 2000, 1000p.

4. BLUMENSCHEIN, Raquel Naves. Gerenciamento de resíduos sólidos oriundos da indústria da construção. Belo Horizonte. 2002.

5. BUENO, Carlos Frederico Hermeto. Tecnologias de materiais de construção. Minas Gerais: UFV, 2000.

6. CONSELHO NACIONAL DO MEIO AMBIENTE. Os Resíduos da Construção Civil, MMA, Proposta de Resolução, Brasília, 2002.

7. D' ALMEIDA, Maria Luiza Otero (Coord.); VILHENA, André (Coord.). Lixo municipal: Manual de gerenciamento integrado. 2. ed. São Paulo: IPT/CEMPRE, 2000.

8. FREITAS, Carlos Geraldo Luz de et al. (Coord). Habitação e meio ambiente: abordagem integrada em empreendimentos de interesse social. São Paulo: Instituto de Pesquisas Tecnológicas - IPT, 2001.

9. FUNDAÇÃO ESTADUAL DO MEIO AMBIENTE. Como destinar os resíduos sólidos urbanos. Belo Horizonte: FEAM, 1995. 47p.

10. GRIGOLI, Ademir Scobin. Entulho de obra: reciclagem e consumo na própria obra que o gerou. Maringá. 1984.

11. LIMA, José Antonio Ribeiro de. Proposição de diretrizes para produção e normalização de resíduo de construção reciclado e de suas aplicações em argamassas e concretos. 1999. 240f.. Dissertação (Mestrado em Arquitetura e Urbanismo) - Escola de Engenharia de São Carlos da Universidade de São Paulo, São Paulo.

12. Legislação Brasileira de Resíduos e Ambiental Correlata. Brasília: Senado Federal 2001. $v$ - (Caderno Legislativo; n. 4)

13. NOGUEIRA, Tânia. A lei do entulho. Revista Época. São Paulo, n. 315, 2004.

14. PETRUCCl, Eladio G. R. Materiais de construção. 12 ed. São Paulo: Globo, 1998.

15. PINTO, Tarcísio de Paulo (Coord.). Gestão ambiental de resíduos da construção civil: A experiência do Sinduscon-SP. São Paulo: Sinduscon, 2005. 48p.

16. Metodologia para a gestão diferenciada de resíduos sólidos da construção urbana. São Paulo, 1999. Tese (doutorado) - Escola Politécnica, Universidade de São Paulo, 189p.

17. ZORDAN, Sérgio Eduardo. Reciclagem de entulho da indústria de construção civil. 